\title{
O SEQUESTRO DE CARBONO EM TRECHOS DA FLORESTA URBANA DE BELO HORIZONTE: POR UM SISTEMA DE ESPAÇOS LIVRES MAIS EFICIENTE NO PROVIMENTO DE SERVIÇOS ECOSSISTÊMICOS URBANOS
}

\author{
CARBON SEQUESTRATION IN STRETCHES OF BELO HORIZONTE'S URBAN FOREST: \\ FOR A MORE EFFICIENT OPEN SPACES SYSTEM IN THE PROVISION OF \\ URBAN ECOSYSTEM SERVICES
}

Rubens Amaral*

Staël de Alvarenga Pereira Costa**

Maria Rita Scotti Muzzi***

\begin{abstract}
RESUMO
Este artigo objetiva estudar o papel das florestas urbanas na provisão de serviços ecossistêmicos urbanos por meio da análise do sequestro de carbono em áreas diferenciadas, no sistema de espaços livres da cidade de Belo Horizonte, procurando ofertar indicadores de qualidade de serviços ambientais e subsidiar a proposição de diretrizes paisagísticas direcionadas à sua implantação ou melhoria. Pela interpretação e aplicação de princípios e métodos relacionados ao estudo da paisagem - em especial aqueles das escolas da morfologia urbana e da ecologia da restauração -, foi possível a escolha para estudo de caso dos seguintes trechos de floresta urbana: o Parque Municipal das Mangabeiras, a praça Raul Soares e o Parque Municipal Américo Renê Giannetti. Nessas áreas estimou-se a biomassa vegetal e do solo, assim como a concentração de substâncias húmicas e de isótopos estáveis de carbono e nitrogênio do solo. Os resultados obtidos foram analisados criticamente em relação aos processos morfológicos e à concepção e tratamento paisagístico de cada área. Com base nisso, delinearam-se diretrizes paisagísticas orientadas para a introdução e melhoria da prestação de serviços ecossistêmicos urbanos em trechos diferenciados de floresta urbana.

Palavras-chave: Floresta urbana. Sequestro de carbono. Serviços ecossistêmicos urbanos. Morfologia urbana. Ecologia da restauração. Paisagens urbanas.
\end{abstract}

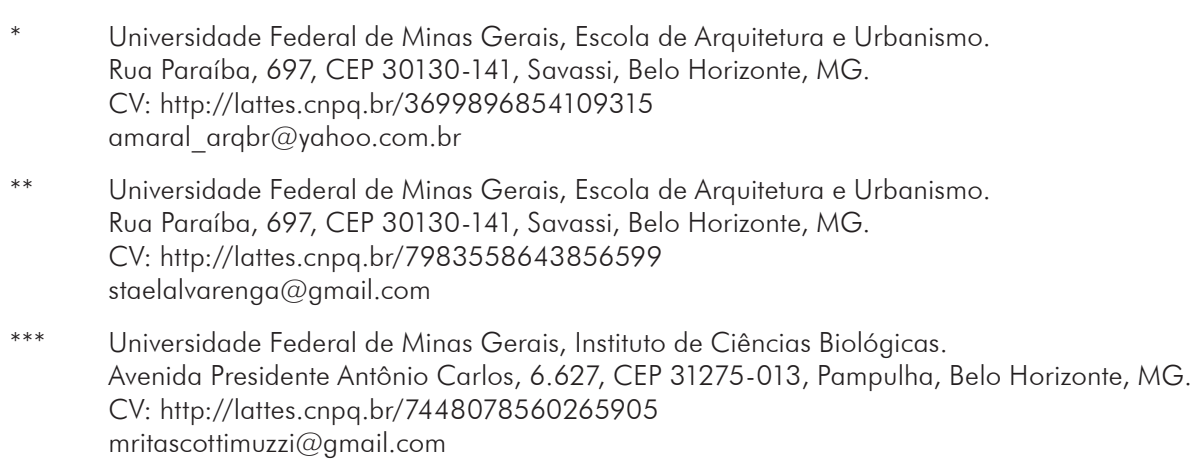




\section{ABSTRACT}

This article seeks to study the role of urban forests in the provision of urban ecosystems through the analysis of carbon sequestration in differentiated open spaces located in the city of Belo Horizonte. It aims to offer quality indicators regarding environmental services and support the proposal for enhanced landscape guidelines for new or regenerated areas. Through the interpretation and application of landscaping principles and methods, particularly those from the schools of Urban Morphology and Restoration Ecology, the following urban forests were selected as case studies: Parque Municipal das Mangabeiras, Praça Raul Soares and Parque Municipal Américo Renê Giannetti. Their biomasses were estimated and soil samples were collected and sent to a laboratory to be tested for soil fertility, concentration of humic substances and analysis of stable isotopes. The results went through a critical analysis of both their morphological processes and their design and landscaping. Based on that information this article outlines a few landscaping guidelines in order to introduce and improve the provisions of urban ecosystem services in differentiated parts of the urban forest. Keywords: Urban forest. Carbon sequestration. Urban ecosystemic services. Urban morphology. Restoration ecology. Urban landscapes.

\section{INTRODUÇÃO}

Pode-se entender como 'floresta urbana' a soma de toda vegetação arbórea a ela associada, existente em assentamentos urbanos ou a eles circundantes. Tanto oriunda de intervenções paisagísticas quanto dos processos de sucessão vegetal, inclui a vegetação ao longo de ruas e em parques urbanos; em áreas abandonadas ou no interior dos lotes; em manchas florestais remanescentes ou em áreas de reflorestamento. Trata-se de elemento dinâmico que, conforme os critérios e fases de desenvolvimento da paisagem urbana, apresenta significativa diversidade de espécies sob os mais variados impactos - positivos ou negativos (NOWAK; CRANE, 2002; ALVEY, 2006; NOWAK, 2006; McNEIL; VAVA, 2006; WU, 2008; SCHWAB, 2009; WALSH, 2012).

Em uma floresta, o sequestro de carbono (C) em biomassa aérea e pelo solo é um dos principais serviços ecossistêmicos florestais cujo entendimento propicia a instrumentalização do aumento de absorção biológica de carbono no planeta. Configura-se também como indicador do grau de implantação desses serviços: o estabelecimento do ciclo de carbono e nutrientes ao longo das florestas urbanas equilibra a relação entre solo e vegetação, gerando quantidades maiores e mais qualificadas de matéria orgânica. No solo, parte desta é transformada em substâncias húmicas, que representam o estoque definitivo de carbono no solo. Estima-se que o montante sequestrado chega a mais de quatro vezes o volume estocado em biomassa vegetal e no solo se relacionam com a implantação de serviços ecossistêmicos no meio ambiente. A matéria orgânica húmica aumenta a fertilidade do solo e favorece o sequestro de carbono e o crescimento das plantas. Promove também a agregação e equilibra a porosidade do solo, o que resulta em melhor crescimento vegetal, controle da erosão e maior drenagem, com consequente manutenção dos aquíferos. Esse estoque de matéria orgânica húmica no solo constitui a principal via de sequestro de carbono no solo, que é muito superior ao sequestrado na biomassa aérea.

Esses serviços ecossistêmicos podem ser relacionados a outros, inerentes à presença de vegetação - principalmente arbórea - nas cidades, tais como melhoria microclimática, conservação da biodiversidade, fertilidade do solo, produção de alimentos, 
O Sequestro de Carbono em Trechos da Floresta Urbana de Belo Horizonte: por um Sistema de Espaços Livres mais Eficiente no Provimento de Serviços Ecossistêmicos Urbanos

absorção de polventes e partículas, prevenção e redução da erosão, purificação da água e alívio da polvição sonora. Enquadrar-se-iam como serviços ecossistêmicos urbanos - aos quais também se agregam os de natureza recreativa, educativa e estética - relacionados ao potencial de interação cultural das florestas urbanas com as populações das cidades (BALÉE, 1989; GILL et al., 2007; BONAM, 2008; WU, 2008; MACEDO et al., 2009; TREVISAN et al., 2010; RONQUIN, 2010; WICK; INGRAM; STAHL, 2010; LOVELL; TAYLOR, 2013; LAL, 2004). A figura 1 apresenta de forma generalizada o fluxo de carbono em um ecossistema terrestre e os pontos principais de sequestro desse elemento, relacionados com os serviços ecossistêmicos supracitados.

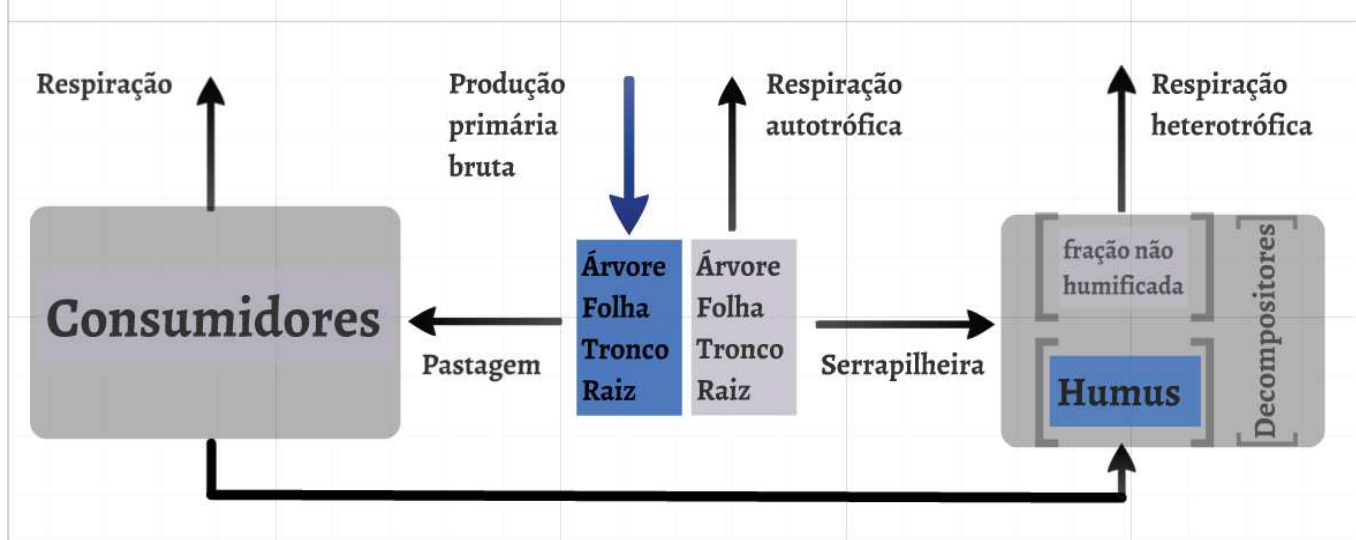

Figura 1 Representação generalizada dos componentes de um ecossistema terrestre - todos conectados pelo fluxo de carbono. Em azul encontram-se relacionados os pontos em que o carbono é imobilizado no processo. Fonte: Bonam (2008).

Objetiva-se, assim, por meio de estudo de caso ao longo da floresta urbana de Belo Horizonte, clarificar a relação entre a configuração desse elemento na paisagem e a prestação de serviços ecossistêmicos, relacionados com sequestro de carbono na biomassa florestal e no solo -, fornecer indicadores de qualidade de serviços ambientais com base em tipos contrastantes de floresta urbana e propor diretrizes paisagísticas direcionadas à implantação ou melhoria de serviços ecossitêmicos urbanos.

Também procura-se trazer entendimento sobre o fluxo vertical de energia e matéria, instrumentalizando a melhoria ou introdução dessas funcionalidades no padrão estrutural da paisagem urbana. Atribui-se, nesse processo, a percepção da floresta urbana como infraestrutura verde de caráter multifuncional, instrumento para a melhoria da qualidade de vida nos aglomerados urbanos. Através deste estudo, contribui-se para a proposição de um design paisagístico alinhado ao paradigma da sustentabilidade e à resiliência urbana (FORMAN; GODRON, 1986; PELLEGRINO, 2000; HOBBS, 2003; LOVELL; TAYLOR, 2013).

Tal alinhamento pode ser subsidiado pelo enlace interdisciplinar entre os referenciais teóricos relacionados a estudos da paisagem - em especial os da Escola Inglesa de Morfologia Urbana e da Escola da Ecologia da Paisagem, e da recente Escola da 
Ecologia da Restauração. Todas, conjugadas, propiciam abordagens integrais sobre o processo de formação da floresta urbana.

\section{ESTUDO DE CASO}

Belo Horizonte é o município estruturador da Região Metropolitana de Belo Horizonte (RMBH) - atualmente composta por 34 cidades (RMBH, 2014) -, instituída pela Lei Complementar do Brasil n 14, de 8 de junho de 1973. De acordo com a figura 2, o município é dividido em nove Regiões Administrativas: Barreiro, Centro Sul, Leste, Nordeste, Noroeste, Norte, Oeste, Pampulha e Venda Nova. Seus limites e formas de gestão foram estabelecidos pela Lei Municipal n 4.158/85, e seus perímetros ajustados pela Lei Municipal 10.231/2011 (BELO HORIZONTE, 2014; BELO HORIZONTE, 2011).

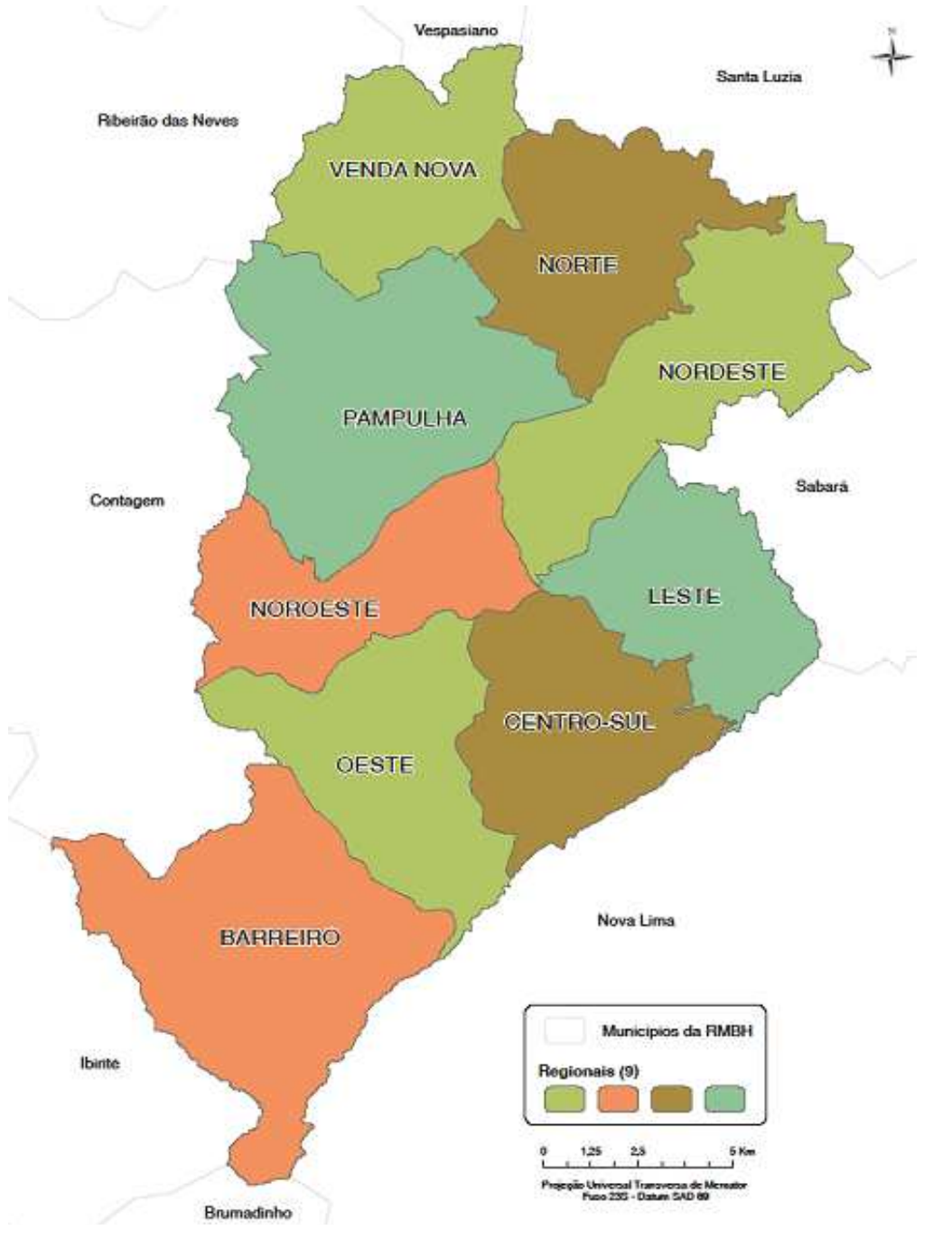

Figura 2 Limites do município de Belo Horizonte e divisão administrativa municipal. Fonte: Prefeitura de Belo Horizonte (2014). 
O Sequestro de Carbono em Trechos da Floresta Urbana de Belo Horizonte: por um Sistema de Espaços Livres mais Eficiente no Provimento de Serviços Ecossistêmicos Urbanos

Entre tais regiões, a área incidente sobre a Administração Regional Centro-Sul demonstra-se propícia para a seleção de trechos de floresta urbana com diferenças e contrastes no grau de implantação de serviços ecossistêmicos. Os aspectos geomorfológicos das áreas, atinentes ao detalhamento das grandes unidades de relevo - Depressão de Belo Horizonte e Serras do Quadrilátero Ferrífero - apontam para o contraste das fisionomias topográficas existentes entre elas. Essas unidades podem ser subdivididas em compartimentos de relevo, com especificidades relacionadas a três linhas de fixação originárias do sistema natural: 1) ribeirão Arrudas, incidente sobre o compartimento de relevo Várzea do Arrudas; 2) falha de empurrão entre as grandes unidades de relevo - Depressão de Belo Horizonte e Serras do Quadrilátero Ferrífero; 3) falhas de empurrão nas cotas mais altas do compartimento de relevo Cristas da Zona Sul (FERREIRA, 1998; CARVALHO, 2001; PRODABEL, 2014).

Coerentemente, as formações vegetais, que teriam sido incidentes sobre esses compartimentos de relevo antes da implantação do sistema antrópico, apresentam graus de complexidade e variabilidade condizentes com a geomorfologia da área. A paisagem teria sido composta por predominância de espécies de cerrado nas cotas mais baixas, e de mata atlântica nas mais altas - embora todas imbricadas em um arranjo complexo, com vegetação densa e predominância de formações florestais (FERREIRA, 1998; CARVALHO, 2001; ARAÚJO FILHO, 2014; RIBEIRO; WALTER, 2014).

Mas, no estudo dos processos morfológicos relacionados à implantação do sistema antrópico na área, observa-se que o plano urbano proposto por Aarão Reis apresentou diferenças na escala dos tecidos urbanos, condicionadas pelo sistema natural. $\mathrm{Na}$ área interna à avenida do Contorno - antiga zona urbana -, verifica-se apenas um padrão predominante de parcelamento do solo, de traçado ortogonal, caracterizado pela ignorância das especificidades do sítio. Na área externa à avenida do Contorno - antiga zona suburbana -, os atributos do sítio teriam configurado maior diversidade de tecidos urbanos (BARRETO, 1995; FUNDAÇÃO JOÃO PINHEIRO, 1997; MACIEL, 1998; PEREIRA COSTA; MACIEL, 2009).

Assim, na Administração Regional Centro Sul, pela conjunção dos aspectos supracitados, apresentam-se os seguintes trechos de floresta urbana a serem analisados. Como área de referência, ao longo da linha de fixação da falha de empurrão confrontante com as Cristas da Zona Sul, indica-se a unidade de faixa de hiato urbano - fringe belt ${ }^{1}$ - externa ao Parque Municipal das Mangabeiras (PMM) [(M. R. G. CONZEN, 1966; M. P. CONZEN, 2001; HOPKINS, 2003; WHITEHAND, 2013)].

Como modelo de maior contraste para comparação com o PMM, aponta-se uma área dentro do compartimento de relevo Várzea do Arrudas: a praça Raul Soares. $\bigcirc$

Zonas periféricas e sucessivas que contornavam uma urbanização medieval, cristalizando os processos expansivos da cidade com usos do solo distintos do residencial. Sempre intercalado por áreas predominantemente residenciais, esse fenômeno é também identificado nas cidades contemporâneas, constituindo faixas mais irregulares e menos estruturadas, apresentando menor ordenamento do que o parcelamento que as circunda ou intercala. Podem ser relacionadas com o processo de estagnação e posterior expansão da dinâmica imobiliária. Conforme a ocorrência desses ciclos, é possível classificar as faixas de hiatos urbanos - fringe belts - como internos, intermediários e externos. 
compartimento abrigou significativo estrato de vegetação dos tipos cerradão e mata ciliar. Contudo, as superfícies suaves da praça aparentam grave supressão da camada de vegetação e apagamento dos serviços ambientais anteriormente prestados pelo sítio.

Como modelo intermediário de comparação entre as duas áreas, adota-se, no mesmo compartimento de relevo da praça Raul Soares, e ao longo da linha de fixação do ribeirão Arrudas, a unidade e faixa de hiato urbano - fringe belt - interno ao Parque Municipal Américo Renê Giannetti (PMARG). O parque destacou-se por ser uma das poucas áreas, no tecido urbano interno à avenida contorno, cujo sistema antrópico buscou certa adequação às características do compartimento de relevo em que se encontra, além de oferecer superfícies suaves com tratamentos paisagísticos heterogêneos.

A figura 3 apresenta a indicação das áreas selecionadas para estudo na Região Administrativa Centro Sul, conforme os compartimentos de relevo ao qual pertencem, e as linhas de fixação existentes na área. Destacam-se as áreas relacionadas ao PMARG e ao PMM, que, caracterizados como unidades de faixas de hiato urbano - fringe-belts -, possuem a particularidade de se localizarem ao longo de linhas de fixação originadas pelo sistema natural.

Verifica-se que o processo de implantação do sistema antrópico no PMM oferece indícios de estabilidade e resiliência ambiental, características de uma área de referência apta para estudos de recuperação ecológica. A relação da área com as formas complexas da morfologia urbana - plano urbano, tecido urbano e uso do solo - propiciou, na paisagem de Belo Horizonte, a manutenção de estratos da camada vegetação original. Antes uma área de mineração, a concepção paisagística do parque, por Burle Marx, absorve a componente ecológica e as relações ecossistêmicas - condicionantes do projeto. Estabelece usos e uma relação entre superfícies rígidas, suaves e de água, propícios para a preservação e a recuperação da vegetação existente, tomando o cuidado, inclusive, de introduzir preferencialmente espécies vegetais nativas (PLAMBEL, 1977; MACIEL, 1998; MACEDO; SAKATA, 2002; HOPKINS, 2003; SÁ CARNEIRO, 2010; FARAH, 2010; LOPES et al., 2011; PBH, 2014, PRODABEL, 2014). A figura 4 apresenta a dinâmica das superfícies rígidas e suaves: desde o período anterior à implantação do sistema antrópico, a implantação da estação de tratamento de água do bairro da Serra, a degradação da área pela atividade de mineração a partir de 1962 e a implantação do PMM, vinte anos após, até a contemporaneidade.

Já a praça Raul Soares configura trecho de floresta urbana com indícios de degradação ambiental. A concepção paisagística, associada a outras intervenções realizadas no local, não favorece o fluxo vertical de energia e matéria e a instalação dos serviços ecossistêmicos correlatos. Embora a forma urbana da praça, associada ao tecido urbano, tenha contribuído para a permanência das superfícies suaves, o mesmo não pode ser dito do estrato arbóreo incidente sobre a área. Esta, logo no início do processo de implantação da cidade de Belo Horizonte, teve a camada vegetação original suprimida. Esse quadro, somado à significativa supressão de árvores introduzidas ao longo dos anos, indica um estado de degradação ambiental. Por sua vez, a concepção 
O Sequestro de Carbono em Trechos da Floresta Urbana de Belo Horizonte: por um Sistema de Espaços Livres mais Eficiente no Provimento de Serviços Ecossistêmicos Urbanos

paisagística não se demonstra propícia para mitigar os danos acumulados. $\bigcirc$ modelo neoclássico, com vegetação exótica - introduzida por questões estéticas - contrapõese ao do PMM, originário da observação dos condicionantes ecológicos. Permite o questionamento sobre a funcionalidade ambiental de praças ajardinadas e se esse tratamento paisagístico viabiliza a estabilidade biológica em trechos de floresta urbana (MACIEL, 1998; ROBBA; MACEDO, 2002; HOPKINS, 2003; SÁ CARNEIRO, 2010; SEGAWA, 2010). A figura 5 apresenta o detalhamento da variação da vegetação nas superfícies da praça entre 1936 e a contemporaneidade.

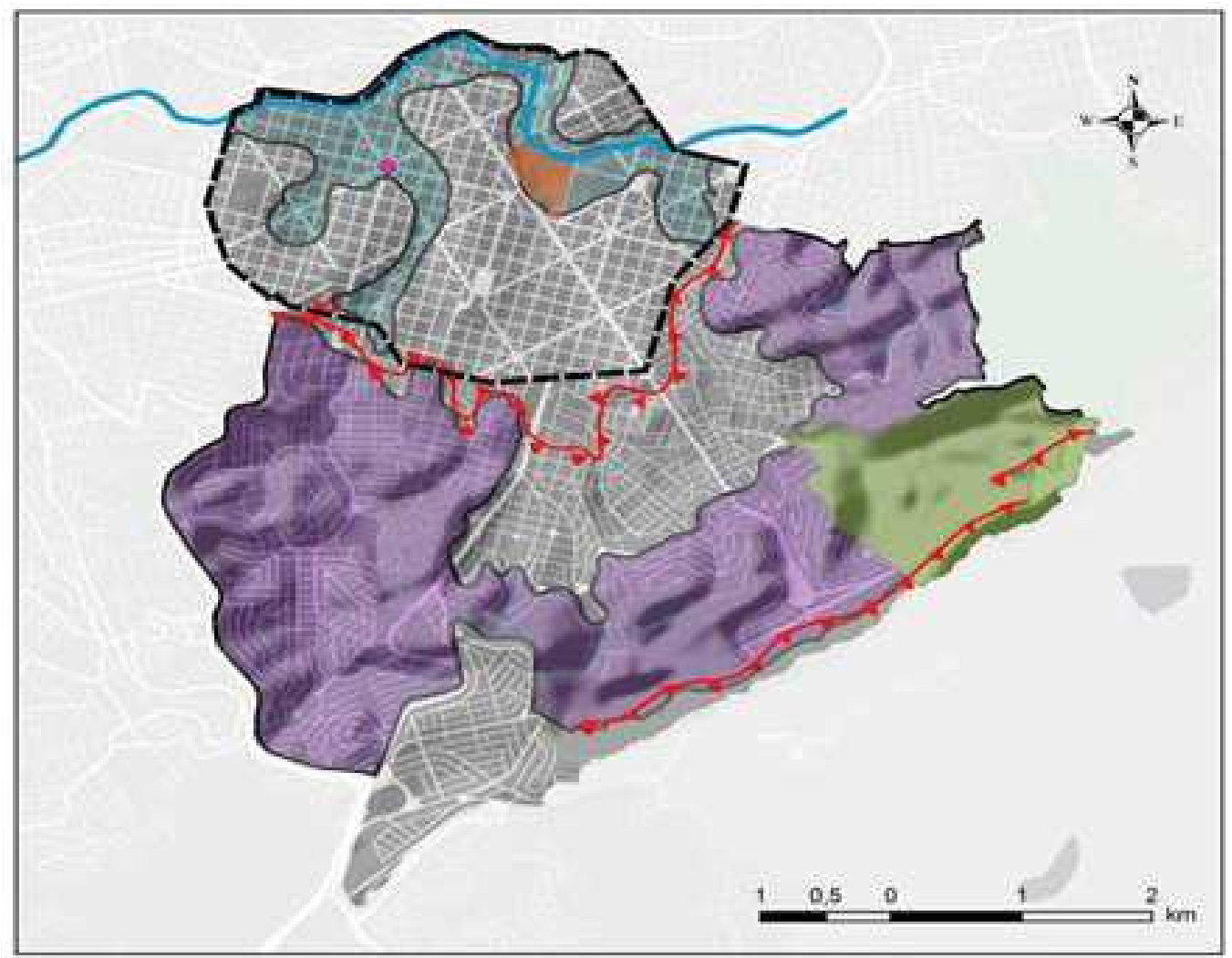

\section{LEGENDA}

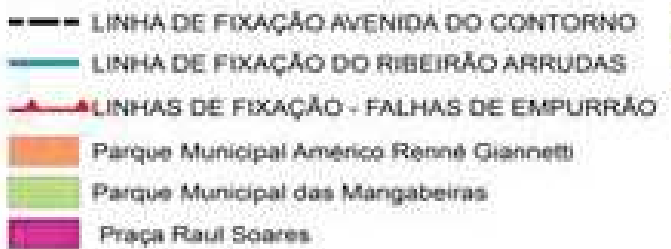

CRISTAS DA ZONA SUL VARZEA DO ARTRUDAS

Figura 3 Áreas selecionadas para análise comparativa no desempenho de sequestro de carbono, com a indicação dos respectivos compartimentos de relevo e das linhas de fixação incidentes sobre a Região Administrativa Centro Sul.

Elaboração: Rubens do Amaral.

Fonte: Ferreira (1998); Carvalho (2001); IBGE (2014); Prodabel ( 2014). 

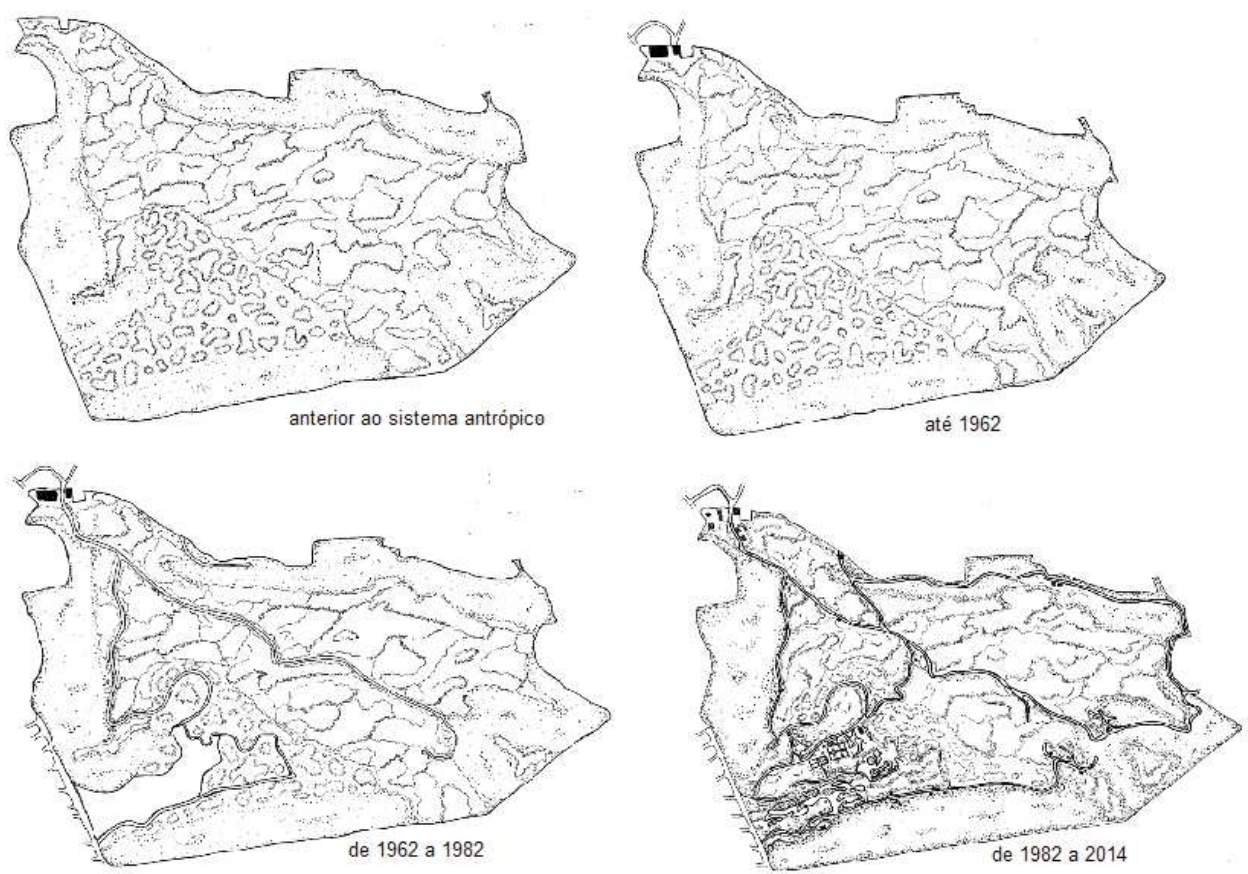

Figura 4 Composição das superfícies da área referente ao PMM anterior à implantação do sistema antrópico, entre 1961 e 1982 e até 2014.

Fonte: Elaborada por Rubens do Amaral e Priscila Lisboa de Paula, 2014.
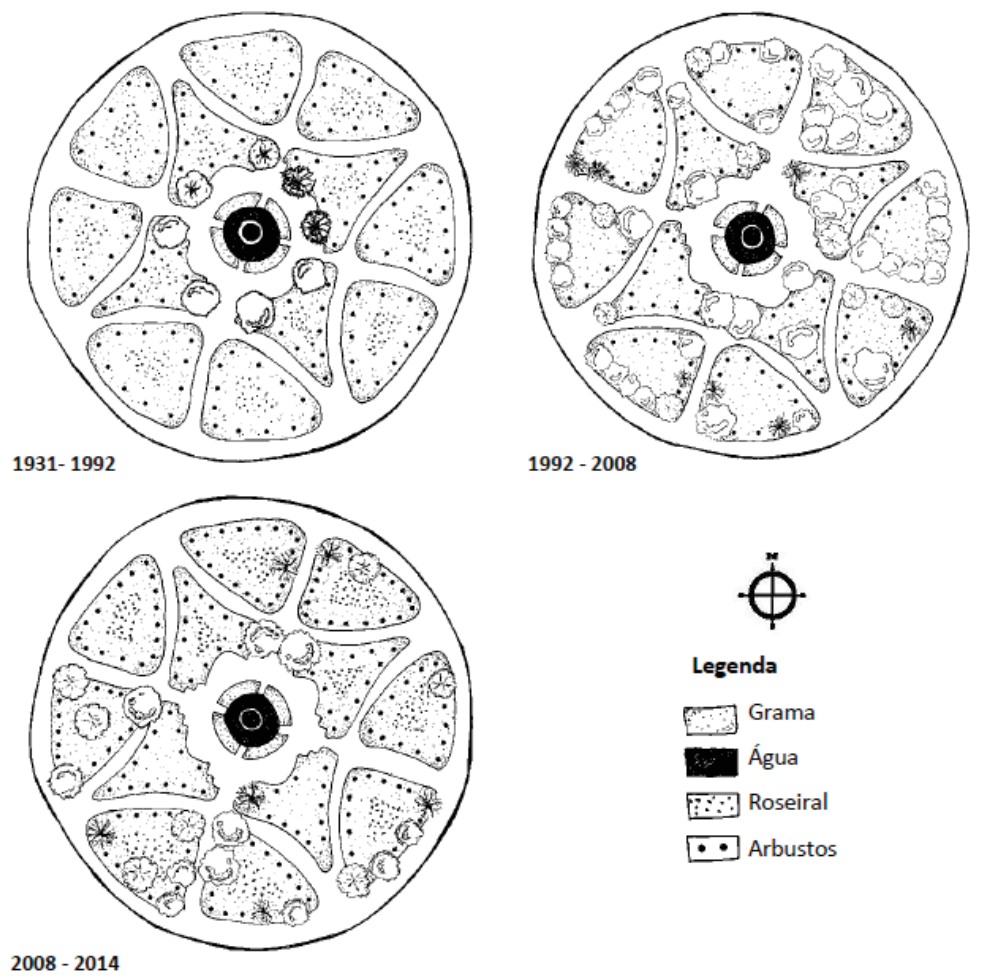

Figura 5 llustração da variação do estrato arbóreo na praça Raul Soares entre 1936 e a contemporaneidade. Fonte: Elaborada por Rubens do Amaral e Priscila Lisboa de Paula, 2014. 
O Sequestro de Carbono em Trechos da Floresta Urbana de Belo Horizonte: por um Sistema de Espaços Livres mais Eficiente no Provimento de Serviços Ecossistêmicos Urbanos

Já o PMARG apresenta-se como uma área de atributos complexos, que requerem estudos sistêmicos e aprofundados. A percepção da tendência de comportamento da área demanda entendimento do grau de implantação de funcionalidades ambientais, em seus diversos habitats, e da interação entre eles. É uma área mista, com tratamento paisagístico que abriga áreas com atributos semelhantes aos do PMM e aos da praça Raul Soares. Além disso, ao longo dos anos, apresentou significativa variação de suas superfícies rígidas, suaves e de água. Nesse processo, características originais do sítio foram apagadas, ultrapassando limiares abióticos, mas, ao mesmo tempo, a área foi intensamente arborizada, sobretudo a partir da década de 1980. Enquanto os corpos d'água foram remanejados, canalizados - e seus terrenos, drenados -, o lençol freático no local permanece superficial, efeito, provavelmente, do significativo estrato arbóreo - mais de 5 mil (COMPANHIA Vale do Rio Doce, 1992; BARRETO, 1995; MACIEL, 1998; MACEDO; SAKATA, 2002; HOPKINS, 2003; FARAH, 2010). A figura 6 apresenta o início da implantação do sistema antrópico na área; a figura 7 , o processo de configuração da vegetação do parque entre os anos de 1938, já nos seus limites atuais, e a contemporaneidade.
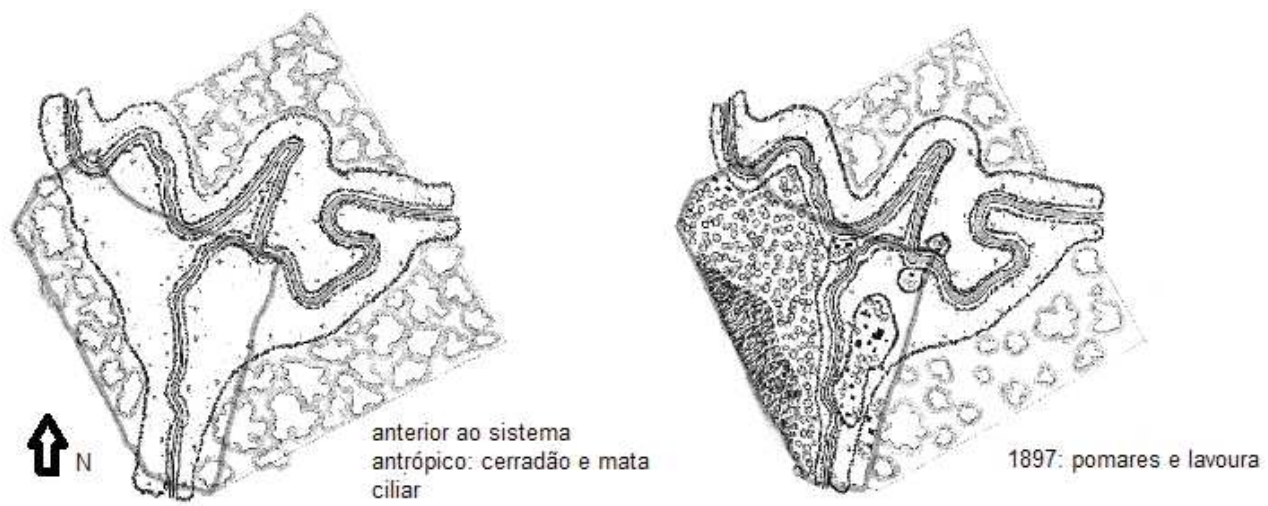

Figura 6 llustração da variação do estrato arbóreo até 1897 em relação ao momento anterior à implantação do sistema antrópico na área do Parque Municipal Américo Renné Giannetti.

Fonte: Elaborada por Rubens do Amaral e Priscila Lisboa de Paula, 2014.
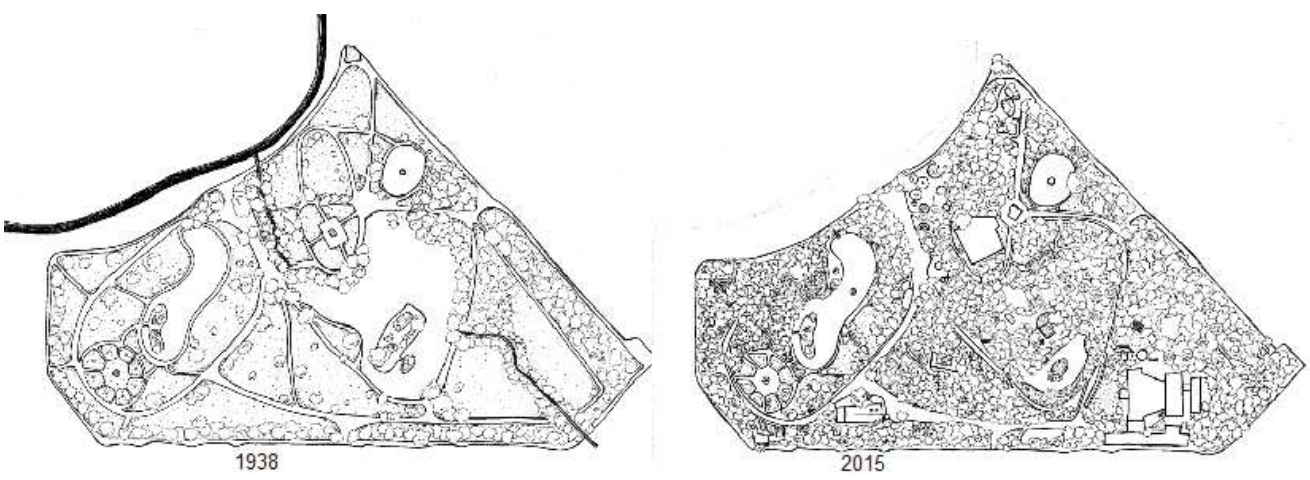

Figura 7 llustração da variação do estrato arbóreo de 1938 até a contemporaneidade no Parque Municipal Américo Renné Giannetti.

Fonte: Elaborada por Rubens do Amaral e Priscila Lisboa de Paula, 2014. 
Assim, nas três áreas observam-se tratamentos paisagísticos diversos, claramente indicativos de estados de preservação e de degradação ambiental. No entanto, em partes das áreas de estudo, em função da heterogeneidade dos tipos de manejo empreendidos, verifica-se que essa relação não é tão explícita. Abre-se, então, a necessidade de aprofundar-se na relação entre trechos diversificados de floresta urbana e os serviços ecossistêmicos prestados.

\section{ANÁLISE CRÍTICA DO ESTUDO DE CASO}

À luz do nexo entre suporte e cobertura e dos processos morfológicos afetos à vegetação em cada trecho de floresta urbana estudado, segue-se a análise conjunta dos processos relacionados ao fluxo vertical de energia e matéria na paisagem. $O$ engate entre essas duas abordagens possibilita investigar os requisitos necessários para a introdução ou melhoria de funcionalidades ambientais na paisagem, relacionados com os serviços ecossistêmicos, inclusive aquelas não perceptíveis, mas cujos indícios se revelam através de indicadores bióticos e abióticos do solo (FORMAN, GODRON, 1986; PELLEGRINO, 2000).

Para analisar os serviços ambientais prestados nas áreas de estudo, foram traçados transectos em cada trecho de floresta urbana, ao longo dos quais foram amostrados blocos de $50 \mathrm{~m}^{2}$, conforme ilustrado na figura 8 .
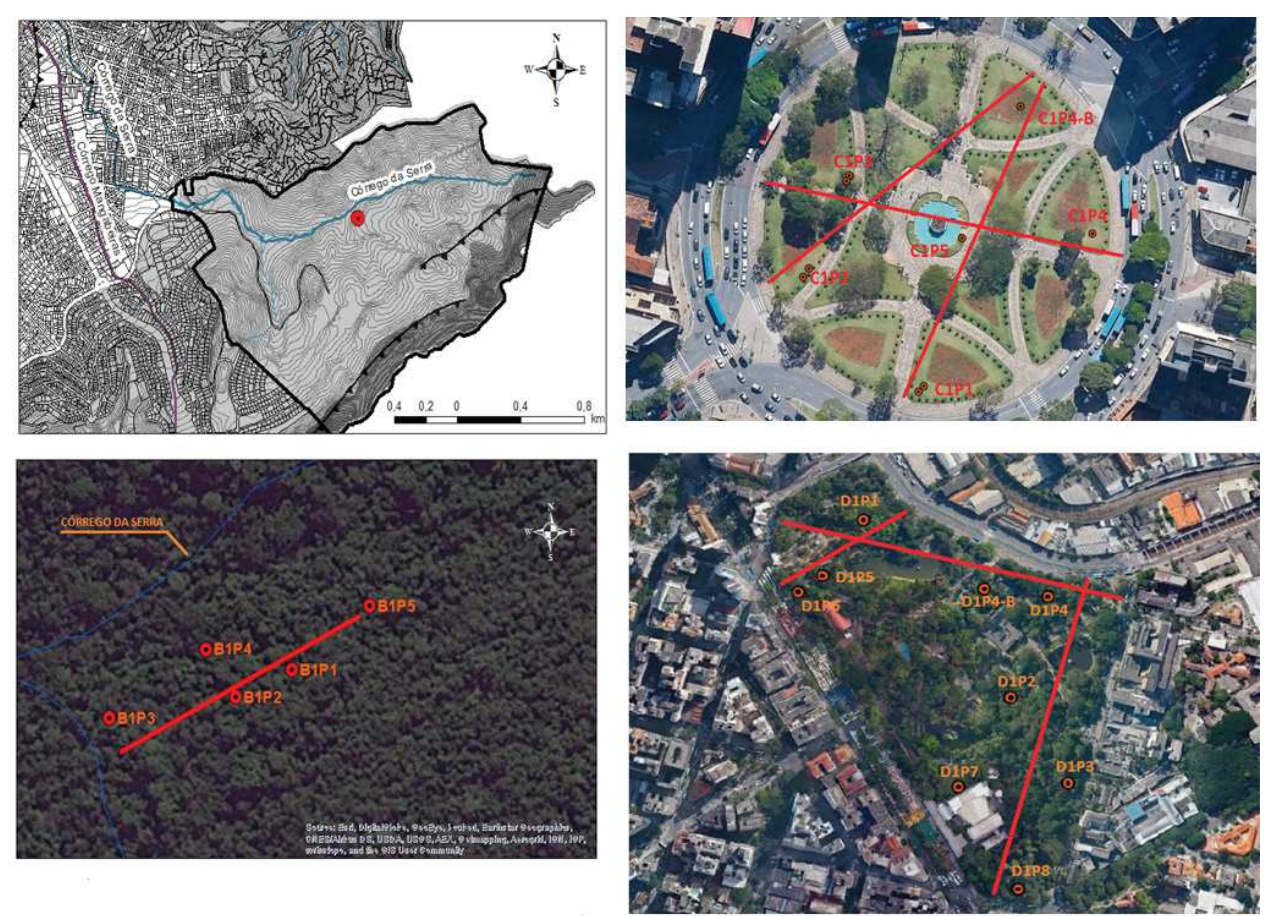

Figura 8 Transectos e respectivos blocos de amostragem nos trechos de floresta urbana estudados. Em sentido anti-horário: a) sítio analisado no PMM; b) transecto PMM; c) transectos PMARG Parque Municipal Américo Renné Giannetti; d) transectos praça Raul Soares.

Elaboração: Rubens do Amaral.

Fonte: Prodabel (2014); Google Earth (2014); ESRI (2014). 
O Sequestro de Carbono em Trechos da Floresta Urbana de Belo Horizonte: por um Sistema de Espaços Livres mais Eficiente no Provimento de Serviços Ecossistêmicos Urbanos

Em cada bloco foi estimada toda biomassa arbórea, de acordo com Arevalo, Alegre e Vilcahuaman (2002). Foram medidos, para a estimativa da biomassa aérea arbórea seca, os diâmetros na altura do peito (DAP) das árvores aptas existentes, e, em cada bloco, amostrou-se uma parcela de $1 \mathrm{~m}^{2}$, na qual foram coletadas porções de vegetação herbácea, da serrapilheira e do solo. Utilizou-se, em cada bloco, um gabarito de $1 \mathrm{~m}^{2}$ para recolhimento de vegetação arbustiva ou herbácea, quando existente, e de $0,25 \mathrm{~m}^{2}$ de serrapilheira, desde que o tratamento paisagístico adotado permitisse sua acumulação. Em todas elas foram recolhidas amostras de solo na profundidade entre $0 \mathrm{~cm}$ e $20 \mathrm{~cm}$, dentro da área demarcada pelo gabarito. A figura 9 apresenta um esquema das parcelas amostradas nos trechos de floresta urbana estudado.

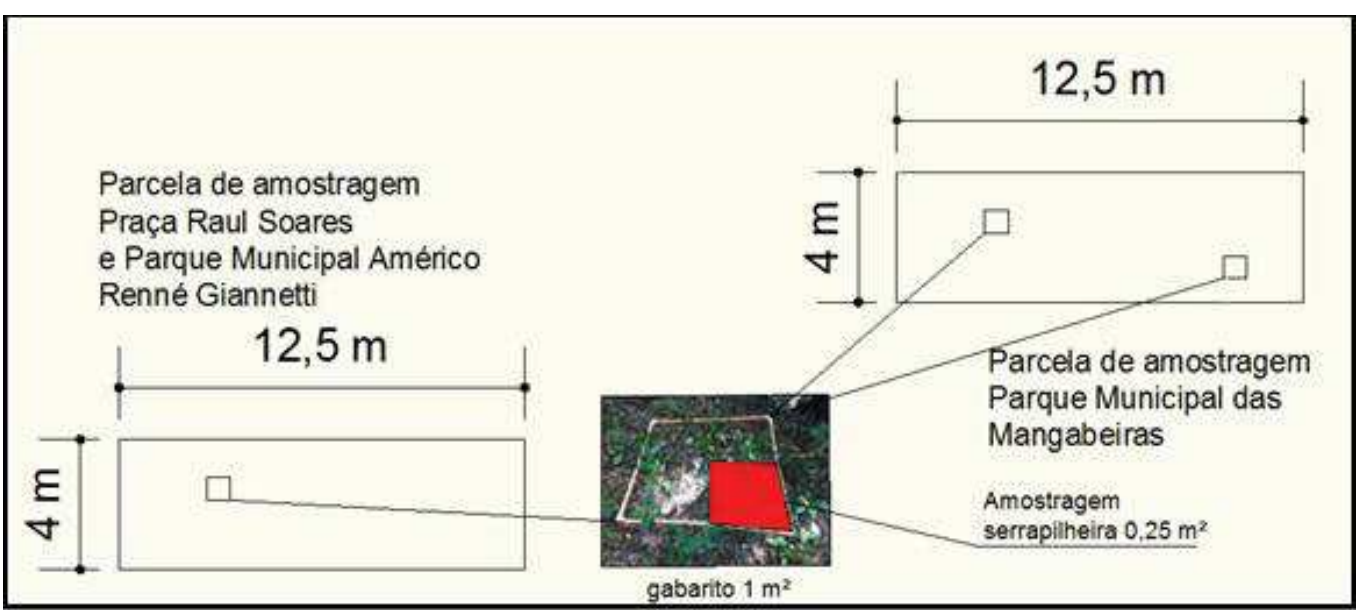

Figura 9 Esquema das parcelas para a análise dos diferentes componentes da biomassa vegetal nos trechos de floresta urbana estudados.

Fonte: Elaborado por Rubens do Amaral, 2014.

Para o cálculo da biomassa arbórea, utilizou-se a equação alométrica estabelecida pelo Intergovernmental Panel on Climate Change (IPCC) 2003 para estimativa de biomassa arbórea em florestas tropicais úmidas com precipitação entre 2.000 e 4.000 milímetros ao ano.

Em relação às amostras de solo, foram realizadas as seguintes análises: fertilidade do solo (WALKLEY; BLACK, 1934); fracionamento da matéria orgânica do solo pelo método de Dabin (1981) e medição de isótopos estáveis de C e N (carbono e nitrogênio) do solo, utilizando espectrômetro de massa de razão isotópica (WERNER; BRAND, 2001; COLORADO, 2014).

Do conjunto das análises realizadas foram obtidas as seguintes variáveis: carbono em biomassa arbórea (Cba), carbono em serrapilheira (Cbs), carbono em biomassa herbácea ou arbustiva (Cha), número de árvores ( $N^{\circ}$ arv), carbono orgânico total no solo (Corg), percentual de carbono no solo (\%C), percentual de nitrogênio no solo $(\% \mathrm{~N})$, carbono em ácido húmico (Cah), carbono em ácido fúlvico (Caf), relação carbono:nitrogênio $(\mathrm{C} / \mathrm{N})$, carbono isotópico $13\left(\mathrm{~d}^{13} \mathrm{C}\right)$ e nitrogênio isotópico $15\left(\mathrm{~d}^{15} \mathrm{~N}\right)$. Visando ao traçado de indicadores de qualidade de serviços ambientais, as variáveis 
demostraram-se hábeis para análises objetivas do grau de implantação de serviços ecossistêmicos urbanos nas áreas de estudo.

No gráfico 1 - mapa perceptual via componentes principais - observa-se a dispersão das áreas estudadas de acordo com as variáveis examinadas. No grupo 1 (em verde) estão sinalizados os pontos de amostragem no PMM. Tal área, de acordo com os resultados encontrados, dista-se do PMARG, representado pelo grupo 2 (em vermelho), que ocupa uma posição intermediária com maior proximidade da praça Raul Soares (PRS), por sua vez representada no grupo 3 (em azul), mais distante e separada do grupo 1. De acordo com o mapa perceptual, via componentes principais dessas variáveis é possível verificar a correlação entre elas e o desempenho dos trechos de floresta urbana estudados na prestação de serviços ecossistêmicos.

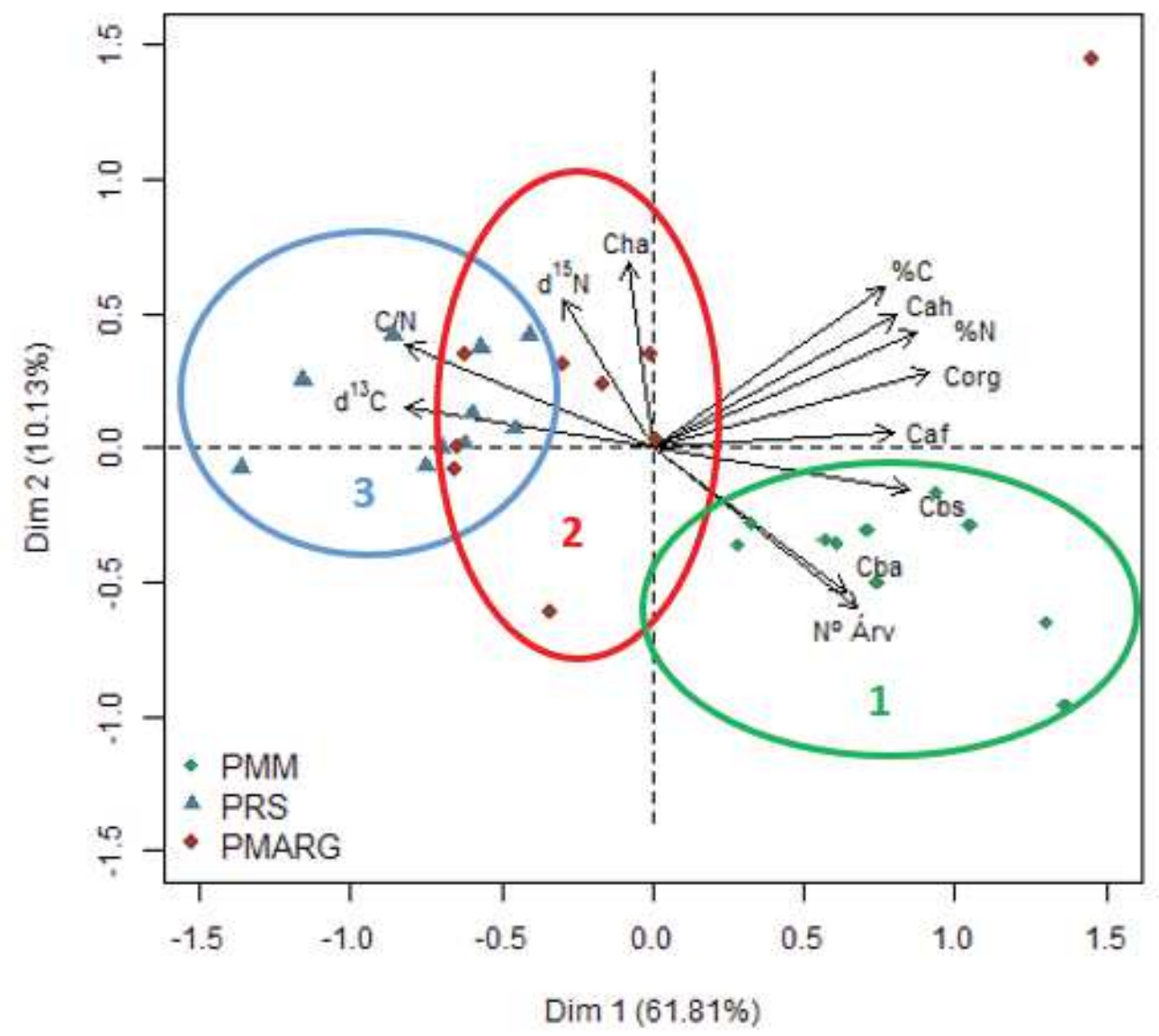

Figura 10 Mapa perceptual via componentes principais para as variáveis, indicando a correlação entre as variáveis estudadas no PMM (grupo 1), no PMARG (grupo 2) e na praça Raul Soares, PRS (grupo 3).

Execução: ABG Consultoria Estatística. Fonte: Rubens do Amaral, 2014.

Entre as variáveis qualitativas estudadas, as que se apresentam mais relacionadas com a implantação do ciclo biológico de carbono e paralelo de nutrientes foram: $\% \mathrm{C}$, Cah e \% $\mathrm{N}$ - positivamente correlacionadas ao sequestro de carbono -, e $\mathrm{d}^{13} \mathrm{C}$, juntamente com $\mathrm{C} / \mathrm{N}$ - negativamente correlacionadas. 
O Sequestro de Carbono em Trechos da Floresta Urbana de Belo Horizonte: por um Sistema de Espaços Livres mais Eficiente no Provimento de Serviços Ecossistêmicos Urbanos

\section{DISCUSSÃO DOS RESULTADOS}

Pelas análises realizadas, o PMM ratificou-se como área de referência, com os maiores valores das variáveis \% N, Cah, \%C e os menores valores das variáveis d13C e C/N. A praça Raul Soares, contrastando com o PMM, apresentou os maiores valores das variáveis d $13 \mathrm{C}$ e $\mathrm{C} / \mathrm{N}$, indício de ineficácia na prestação de serviços ambientais. Já - PMARG, com características afins às duas áreas, posiciona-se intermediariamente, mas com comportamento ainda próximo ao da praça Raul Soares. Isso se deve à influência das áreas gramadas do parque e o uso de adubação química. Mas a quantidade de matéria húmica existente (Cah) e a arborização intensa realizada no parque ao longo dos anos, ofertariam indícios de uma tendência de comportamento em direção ao da área de referência.

A análise comparativa realizada, somada às informações referentes ao processo de configuração da paisagem em cada trecho de floresta urbana estudado, subsidiou o delineamento de diretrizes paisagísticas baseadas no provimento de serviços ecossistêmicos relacionados ao sequestro de carbono. Seguem diretrizes paisagísticas gerais para a introdução ou melhoria do fluxo vertical de energia em qualquer trecho de floresta urbana, com impactos positivos em relação aos serviços ecossistêmicos urbanos prestados:

- acréscimo de árvores;

- preservação de árvores mais antigas, evitando ao máximo a supressão de exemplares;

- formação de camada de serrapilheira sob as árvores (condição sine qua non para a introdução plena do ciclo de carbono e do paralelo de nutrientes nessas áreas);

- introdução de plantas da família das leguminosas, procurando evitar a utilização de adubos químicos (medida importante para a melhoria da fertilidade dos trechos de floresta urbana).

Como diretrizes decorrentes da observação dos atributos paisagísticos de cada área, destacam-se:

- preservar unidades de faixas de hiato urbano - fringe belts - ao longo do território;

- expandir e qualificar as superfícies suaves ao longo dos tecidos urbanos, com tratamento paisagístico direcionado para a melhoria dos serviços ecossistêmicos prestados;

- priorizar a preservação e recuperação de estratos da camada de vegetação original e das relações do ecossistema em que estão inseridos;

- a implantação de arborização e demais formas de vegetação deve ser balizada pelo serviço ecossistêmico urbano desejado para a área;

- em intervenções paisagísticas, priorizar a implantação de espécies arbóreas em vez de arbustivas e utilizar com cautela o uso de forrações; 
- intervenções devem considerar como sistema composto por vários habitats áreas com tratamento paisagístico heterogêneo, com diversos graus de implantação das funcionalidades ambientais.

Para a efetividade das diretrizes sugeridas com base nos indicadores estudados, propõem-se também diretrizes para o monitoramento da prestação de serviços ecossistêmicos urbanos em trechos de floresta urbana.

As metas, por sua vez, devem ser balizadas por indicadores capazes de informar o grau de implantação dos serviços ambientais nas áreas de intervenção. Sugere-se que sejam traçadas por meio dos seguintes indicadores qualitativos: percentual de carbono no solo, percentual de nitrogênio no solo, carbono em ácido húmico, razão C:N e percentual de carbono isotópico 13, todos já recomendados pelo estudo como as melhores variáveis para aferição de serviços ecossistêmicos, imbricadas com as diretrizes paisagísticas gerais.

\section{CONSIDERAÇÕES FINAIS}

Este estudo contribui para a pesquisa interdisciplinar, propiciando a cooperação entre campos de estudos afetos ao urbanismo e às ciências biológicas. Isso foi possível pela cooperação entre os preceitos e métodos apontados principalmente pelas Escolas de Morfologia Urbana Inglesa, Ecologia da Restauração e da Ecologia da Paisagem.

A abordagem aqui utilizada clarificou formas de investigação do grau de implantação de serviços ecossistêmicos urbanos em trechos de floresta urbana, possibilitando o traçado e o monitoramento de intervenções paisagísticas voltadas para a melhoria do desempenho ambiental de tais trechos, propondo diretrizes paisagísticas orientadas para a funcionalidade ambiental da floresta urbana - e não decorrentes de uma abordagem unicamente estética de tratamento dos espaços livres.

Assim, percebe-se uma possibilidade de manejo da vegetação nas cidades, em especial da arbórea, não destinada apenas à criação de ambiências amenas, mas objetivamente orientada para a implantação de serviços ecossistêmicos urbanos. Permite trazer, para a formulação e gestão do meio urbano, planos, programa, projetos e ações para a mitigação da emissão de gases de efeito estufa e promover estratégias de adaptação aos impactos da mudança do clima. As diretrizes traçadas, uma vez consolidadas em instrumento normativo, poderiam orientar e avaliar modificações na estrutura e função dos espaços livres intraurbanos. Abrem-se possibilidades para, objetivamente, viabilizar a ampliação de sumidouros e reservatórios de gases de efeito estufa e buscar a eficiência de tais áreas na drenagem urbana, na imobilização de polventes e na mitigação e ilhas de calor, entre outros serviços ecossistêmicos urbanos. 
O Sequestro de Carbono em Trechos da Floresta Urbana de Belo Horizonte: por um Sistema de Espaços Livres mais Eficiente no Provimento de Serviços Ecossistêmicos Urbanos

\section{REFERÊNCIAS BIBLIOGRÁFICAS}

ALVEY, A. A. Promoting and preserving biodiversity in the urban forest. Urban Forestry \& Urban Greening, v. 5, 2006, p. 195-200.

AREVALO, L. A.; ALEGRE, J. C.; VILCAHUAMAN, L. J. M. Metodologia para estimar o estoque de carbono em diferentes sistemas de uso da terra. Colombo: Embrapa Florestas, 2002. Disponível em:

<http://www.reciclecarbono.com.br/biblio/metod_embrapa.pdf>. Acesso em: 4 fev. 2014.

ARAÚJO FILHO, J. C. Floresta estacional semidecidual. 2014. Disponível em: <http://www.agencia.cnptia. embrapa.br/gestor/territorio_mata_sul_pernambucana/arvore/CONT000gt7eon7l02wx7ha087apz2x2zjco4.html>. Acesso em: 10 dez. 2014

BALÉE, W. Cultura na vegetação da Amazônia brasileira. In: NEVES, W (Org.). Biologia e ecologia humana na Amazônia: avaliação e perspectivas e ecologia humana na Amazônia. Belém: Sociologias, 1989, p. 95-109.

BARRETO, A. Belo Horizonte: memória histórica e descritiva. História Média. Belo Horizonte: Fundação João Pinheiro, 1995.

BELO HORIZONTE. Lei n 10.231, de 20 de julho de 2011 . Dispõe sobre a circunscrição das Regiões Administrativas do Município. Diário Oficial do Município, Ano XVII - Edição N.: 3871, 20 de julho de 2011.

BONAM, G. Ecological climatology: concepts and applications. Cambridge: Cambridge University Press, 2008.

CARVALHO, E. T. Geologia urbana para todos: uma visão sobre Belo Horizonte. Belo Horizonte: Universidade Federal de Belo Horizonte, 2001.

COLORADO Plateau Stable Isotope Laboratory. Isotopes. 2014. Disponível em:

<http://www.isotope.nau.edu/isotope.html>. Acesso em: 27 set. 2014.

COMPANHIA Vale do Rio Doce. Parque municipal: crônica de um século. Belo Horizonte: Companhia Vale do Rio Doce, 1992.

CONZEN, M. R. G. As paisagens urbanas históricas na Inglaterra: um problema de geografia aplicada. The urban landscape: historical development and management. Papers by M. R. Conzen. 1966.

The study of urban form in the United States. Urban Morphology: Journal of the International Seminar on Urban Form. Birmingham, v. 5, 20001, p. 3-14.

DABIN B.: Study of extraction of humic sol organic matter. Science du Sol, 1: 47-63. 1971.

FARAH, I. Arquitetura paisagística no período entre 1976 e 1985. In: FARAH, I.; SCHLEE, M. B.; TARDIN, R (Orgs.). Arquitetura paisagística contemporânea no Brasil. São Paulo: Senac, 2010, p. 77-117.

FERREIRA, M. G. O sítio e a formação da paisagem urbana: um estudo do município de Belo Horizonte. 1997. 183 f. Dissertação (Mestrado) - Instituto de Geociências, Universidade Federal de Minas Gerais, Belo Horizonte, 1998.

FORMAN, R. T. T.; GODRON, M. Landscape ecology. New York: John Wiley \& Sons, 1986.

FUNDAÇÃO João Pinheiro. Panorama de Belo Horizonte: atlas histórico. Belo Horizonte: FJP, 1997. (Coleção Centenário).

GILL, S. E. et al. Adapting cities for climate change: the role of the green infrastructures. Built Environment, v. 33, 2007, p. 115-133. Disponível em: <http://www.fs.fed.us/ccrc/topics/urban-forests/docs/Gill_Adapting_Cities.pdf>. Acesso em: 19 jun. 2013.

HOBBS, R. J. Ecological management and restoration: assessment, setting goals and measuring success. Ecological Management \& Restoration, v. 4, 2003, p. S2-S3.

HOPKINS, M. I. W. Vegetation as a component of urban form. Urban Morphology: Journal of the International Seminar on Urban Form, Birmingham, v. 17, 2013 p. 57-59.

LABORATÓRIO DA PAISAGEM. Os elementos tipo-morfológicos das bordas metropolitanas de Belo Horizonte. Belo Horizonte: Núcleo de Pesquisa em Desenho Ambiental - EA/UFMG, 2013. (Relatório de pesquisa $A P Q-02459-99)$.

$L A L, R$. Soil carbon sequestration impacts on global climate change and food security. Science, New York, v. 304 , 2004, p. 1.623-1.627.

LOPES, M. B. et al. A cidade, seus habitantes e a serra: breves notas sobre a história do Parque das Mangabeiras (1960-2010). 2011. Disponível em: <http://www.vitruvius.com.br/revistas/read/ minhacidade/11.130/3798>. Acesso em: 12 dez. 2014. 
LOVELL, S. T.; TAYLOR, J. R. Supplying urban ecosystem services through multifunctional green infrastructure in the united states. Landscape Ecology in Review, Illinois, v. 28, 2013, p. 1.447-1.463.

MACEDO, S. S.; SAKATA, F. G. Parques urbanos no Brasil. São Paulo: Edusp, 2002.

. et al. Considerações preliminares sobre o sistema de espaços livres e a constituição da esfera pública no Brasil. In: ANDRADE, R.; SCHLEE, M. B.; TÂNGARI, V. R (Orgs.). Sistema de espaços livres: o cotidiano, apropriações e ausências. Rio de Janeiro: FAU-UFRJ, 2009, p. 60-83.

MACIEL, M. C. O projeto em arquitetura paisagística: praças e parques públicos em Belo Horizonte. 1998. 255 f. Tese (Doutorado) - Faculdade de Arquitetura e Urbanismo, Universidade de São Paulo, São Paulo, 1998.

McNEIL, J.; VAVA, C. Oakville's urban forest: our solution to our pollution. Oakville, 2006.

NOWAK, D. J. Institutionalizing urban forestry as a "biotechnology" to improve environmental quality. Urban Forestry \& Urban Greening, Syracuse, v. 5, 2006, p. 93-100.

; CRANE, D. E. Carbon storage and sequestration by urban trees in the USA. Environmental Pollution, Syracuse, v. 116,2002 , pp. 381-389.

PELLEGRINO, P. R. M. Pode-se mudar a paisagem? Paisagem e Ambiente: ensaios. São Paulo: FAUUSP, 2000, p. $158-180$.

PEREIRA COSTA, S. A.; MACIEL, M. C. Fringe belts in planned cities - do they exist in such context? In: SIXTEENTH INTERNATIONAL SEMINAR NO URBAN FORM, 2009, Guangzou: South China University of Technology, 2009a, p. 53.

PLAMBEL. Planejamento da Região Metropolitana de Belo Horizonte. O processo de formação do espaço urbano da RMBH. Belo Horizonte: PLAMBEL, 1977.

PREFEITURA MUNICIPAL DE BELO HORIZONTE (PBH). Parque Municipal das Mangabeiras. 2014. Disponível em: <http://portalpbh.pbh.gov.br/pbh/ecp/comunidade.do? evento=portlet\&pldPlc=ecpTaxonomiaMenuPortal\&ap $\mathrm{p}=$ fundacaoparque\&tax $=15257 \&$ lang $=$ pt_BR\&pg $=5521 \& \operatorname{taxp}=0 \&>$. Acesso em: 27 jan. 2015.

\section{Praça Raul Soares, um centro geográfico de valor arquitetônico e}

cultural. 2014. Disponível em: <http://portalpbh.pbh.gov.br/pbh/ecp/noticia.

$\mathrm{do}_{\text {evento }}=$ portlet\&pAc$=$ not\&idConteudo $=104504 \&$ pldPl $c=\& a p p=$ salanoticias $>$. Acesso em: 27 jan. 2015.

. Regiões Administrativas de Belo Horizonte. 2014. Disponível em: <http://gestaocompartilhada.pbh. $\overline{\mathrm{gov} . \mathrm{br}} / \mathrm{mapas}$-e-estatisticas/mapas-estaticos?term_node_tid_depth=All\&area $=682 \&$ field_formato_tid $=$ All $>$. Acesso em: 27 jan. 2015.

PRODABEL. Base georreferenciada da Regional Administrativa Centro Sul. Arquivos do setor de atendimento. Belo Horizonte, dez/2014. 1 CD-ROM.

RIBEIRO, J. F.; WALTER, B. M. T. Tipos de vegetação do bioma cerrado. 2014.

RMBH. Plano metropolitano: macrozoneamento. RMBH, 2014.

ROBBA, F.; MACEDO, S. S. Praças brasileiras. São Paulo: Edusp, 2002.

RONQUIN, C. C. Conceitos de fertilidade do solo e manejo adequado para regiões tropicais. EMBRAPA, 2010.

SÁ CARNEIRO, A. R. A produção paisagística brasileira entre 1930 e 1976. In: FARAH, I.; SCHLEE, M. B.; TARDIN, R (Orgs.). Arquitetura paisagística contemporânea no Brasil. São Paulo: Senac, 2010, p. 77-117.

SCHWAB, J. Planning the urban forest: ecology, economy and community development. 2009. Disponível em: $<$ http://na.fs.fed.us/urban/planning_uf_apa.pdf $>$. Acesso em: 19 set. 2014.

SEGAWA, H. Arquitetura paisagística até 1930. In: FARAH, I.; SCHLEE, M. B.; TARDIN, R (Orgs.). Arquitetura paisagística contemporânea no Brasil. São Paulo: Senac, 2010, p. 35-48.

TREVISAN, S. et al. Humic substances biological activity at the plant-soi interface: from environmental aspects to molecular factors. Plant Signaling \& Behavior, v. 5, 2010, p. 635-643.

WALSH, A. J. Potential urban forest carbon sequestration and storage capacities in burnside industrial park, Nova Scotia. Minneapolis: Dovetail Partners Inc., 2012.

WHITEHAND, J. W. R. Morfologia urbana britânica: a tradição conzeniana, 2013.

WICK, A. F.; INGRAM, L. J.; STAHL, P. D. Agregate and organic matter dynamics in reclaimed soils as indicated by stable carbon isotopes. Soil Biology \& Biochemistry, v. 41, 2010, p. 201-209.

WALKLEY, A.; BLACK L. A. An examination of the Dgtiareff method for determining soil organic matter, and a proposed modification of the chromic acid titration method. Soil Science, v. 37, 1934, 29-38. 
O Sequestro de Carbono em Trechos da Floresta Urbana de Belo Horizonte: por um Sistema de Espaços Livres mais Eficiente no Provimento de Serviços Ecossistêmicos Urbanos

WERNER, R. A.; BRAND, W. A. Referencing strategies and techniques in stable isotope ratio analysis. Rapid Communications in Mass Spectrometry, v. 15, 2001, p. 501-519.

WU, J. Toward a landscape ecology of cities: beyond building, trees and urban forests. In: CARREIRA, M. M.; GONG, Y.; WU, J (Orgs.). Ecology, planning and management of urban forests: international perspective. Louisville: Springer, 2008, p. 10-28. 